\title{
SATURNO E A MELANCOLIA NO BARROCO A PARTIR DO TRAUERSPIELBUCH DE WALTER BENJAMIN
}

Francisco Fianco

\begin{abstract}
RESUMO
Uma das obras mais importantes de Walter Benjamin é o seu Origem do Drama Trágico Alemão, cujo aspecto mais destacado talvez seja o da melancolia. Pretendemos, neste texto, expandir, a partir daquela obra, outros aspectos, nomeadamente o de imanência e finitude, sem, obviamente, perder de vista a importância da melancolia para o pensamento de Benjamin e para o desenvolvimento de nossa argumentação, a fim de tentar melhor compreender as observações deste pensador sobre o barroco e suas manifestações culturais, como a arte e a literatura.
\end{abstract}

Palavras-chave: Walter Benjamin; Barroco; Melancolia; Finitude; Imanência.

\section{SATURN AND MELANCHOLY IN THE BAROQUE BASED ON WALTER BENJAMIN'S TRAUERSPIELBUCH}

\begin{abstract}
One of Walter Benjamin's most important works is his Ursprung des Deutschen Trauerspiel, whose most prominent aspect is perhaps that of melancholy. In this text, we intend to expand, from that work, other aspects, namely that of immanence and finitude, without, obviously, losing sight of the importance of melancholy for Benjamin's thought and for the development of our argumentation, in order to try better to understand the observations of this thinker about the Baroque and its cultural manifestations, such as art and literature.
\end{abstract}

Keywords: Walter Benjamin; Baroque; Melancholy; Finitude; Immanence. 


\section{Introdução}

Nosso texto tem como tema a interpretação realizada por Walter Benjamin sobre o período barroco e suas manifestações culturais, em especial os aspectos da imanência e da finitude representadas por Saturno, tendo como pano de fundo a melancolia enquanto sentimento de inadequação e desconfiança, característica tida como necessária, senão indispensável, à reflexão filosófica.

Para tanto, seguiremos basicamente o texto de Walter Benjamin, Origem do Drama Trágico Alemão, bem como nos valeremos de análises de obras consagradas como Hamlet, de Shakespeare, por autores não menos consagrados, como Harold Bloom e Jacques Lacan. Para caracterizar um dos efeitos principais da finitude na psique humana, a melancolia, usaremos o texto Luto e Melancolia, de Freud e, no que diz respeito à iconografia, a análise da figura de Saturno enquanto divindade responsável pela melancolia de Fritz Saxl, Erwin Panofsky e Raimond Klibansky, Saturno y la Melancolia.

\section{0 contexto histórico-cultural do século XVII}

Um dos primeiros aspectos que gostaríamos de destacar se refere ao contexto histórico-cultural do período que conhecemos como Barroco, correspondendo majoritariamente ao século XVII na maioria dos países da Europa. Quais foram as mudanças sociais e religiosas que criaram a possibilidade de uma sociedade tão conflitante e paradoxal? Qual o papel da arte, mais especificamente do teatro, nesse contexto? O que tais produções nos permitem apreender do imaginário de então?

Destacamos, portanto, a importância que a história, nesse caso a historicidade, teve para o momento do qual estamos falando, de maneira a entender que os personagens literários representam arquétipos importantes para a compreensão do palco político em questão, de maneira a entender a função do soberano personagem por excelência do drama barroco traz a representação 
para a história, para a temporalidade linear e, o que será fundamental para o desenvolvimento de nossa argumentação, para a finitude.

Segundo Claude-Gilbert Dubois (1995, 195 et seq.) o homem barroco se faz de uma mescla de Idade Média e de Renascimento, e esta dicotomia, com todos os conflitos - psicológicos, filosóficos, estéticos, políticos - que ocasiona, veio se desdobrando ao longo da modernidade. Assim, a emergência do sujeito como ser ativo, não mais substância metafísica sujeita aos desmandos da Providência ou do Destino, o instala como sujeito gramatical, como dotado de capacidade de agir, de posicionar-se frente à natureza, estudá-la, dominá-la. Esta é a inovação principal do humanismo, uma concepção de ser humano onde este é o ponto central das experiências e descobertas. O questionamento da posição tradicional, medieval, da disposição do mundo vai levar a um abandono progressivo destas velhas certezas, simultaneamente ao que a noção de alma humana vai sendo substituída pela noção de consciência, postulando os problemas, agora surgidos, da responsabilidade e da liberdade do ser humano. Esta busca incessante de uma identidade e de uma unidade do sujeito é acompanhada por uma tentativa de se atingir diretamente uma fonte externa ao ser, que é a divindade, mas não como no cenário medieval, onde havia diversos intermediários, anjos, santos, um mundo povoado por demônios, e sim uma comunicação direta entre o homem e o divino, de acordo com as mudanças de perspectiva proporcionadas pela Reforma Protestante, que erigia a opção de que o indivíduo se salvasse através exclusivamente de sua relação com Deus, sem precisar do auxílio ou do intermédio de uma pessoa ou de uma instituição. Sem os intermediários que preencheriam o mundo, a presença divina teria que ser muito forte para poder dar novamente ao mundo o sentido que ele anteriormente tinha. Uma vez que não o consiga, por diversos fatores, como o humanismo e o racionalismo, a melancolia se instaurará através da noção de perda deste sentido que se faz ausente, como se Deus tivesse abandonado o mundo. Este contexto onde o homem se vê sem interlocutor instaura uma introspecção frente a um universo vazio e insensato, concentrando no sujeito as paixões e violências que se retiram do mundano, ampliando a tensão interna a tal ponto que este sujeito não aspire outra coisa senão a explosão, o desejo de destruir-se. 
A melancolia é o sentimento que permeou esta marcha, interiorizando no sujeito a característica mais forte e aterrorizante do Barroco, a imanência. (BENJAMIN, 1984, 161) As observações sobre a melancolia se iniciam pela Reforma Protestante, no ambiente cultural do Renascimento. Cabe agora ao projeto moderno definir o que é o homem, uma vez que não há mais a possibilidade de defini-lo simplesmente como criatura divina conforme ocorrera durante toda a Idade Média. O conceito que se tem do sujeito melancólico no contexto moderno e contemporâneo, é, portanto, fruto das modificações e revoluções de perspectiva ocasionadas pelo Renascimento no campo cultural, artístico e científico, e pela Reforma Protestante no campo antropológico, psicológico e espiritual. "As ações humanas foram privadas de todo valor. Algo de novo surgiu: um mundo vazio." (BENJAMIN, 1984, 162) A Doutrina da Vacuidade das Obras, formulada por Lutero, pregava que a salvação dos cristãos não se dava através das obras ou indulgências que estes fizessem na terra, mas vinculava a salvação única e exclusivamente à fé, da mesma maneira como Deus, segundo ele, já sabia quem seria salvo ou não, quem seria ou não merecedor da redenção.

De acordo com Hatzfeld $(1988,17)$, as condições essenciais para a apresentação de um quadro cultural barroco são: uma Renascença plenamente desenvolvida; o impacto da Reforma Protestante; a presença de uma Contrarreforma católica dominante em diversas áreas, inclusive nas sociais e políticas, e uma integridade de desenvolvimento das artes plásticas e da literatura. Tais características explicariam, de certo modo, a razão pela qual o Barroco, como período artístico cultural, tenha se desenvolvido plenamente em países com forte influência católica, como a Espanha, por exemplo, ou que, por outro lado, se identifiquem as características da arte espanhola do séc. XVII com as do Barroco nos demais países. Assim, as condições culturais propícias para o desenvolvimento de um espírito barroco, originalmente espanhol já estariam presentes na península ibérica desde os escritores hispano-romanos, como o estoico Sêneca, passando pelos místicos espanhóis medievais, como Santa Tereza e San Juan de La Cruz, e culminariam no Barroco com as obras de Calderón de La Barca, cujo pensamento é, de acordo com este mesmo autor, um misto de estoicismo e neo-escolasticismo teológico. Afrânio Coutinho (1994, 
120 et seq.), por sua vez, destaca em poetas como Opitz, já num contexto barroco de países protestantes como a Alemanha, destaca ainda elementos estoicos no espírito do barroco, como a consciência aguda das leis inexoráveis do tempo, segundo as quais tudo está sujeito ao envelhecimento, à morte e à transformação, argumentos assustadores utilizados pelos poetas para convencer as jovens a se entregarem aos prazeres do amor antes que a velhice Ihes arrancassem os encantos e a morte lhes solapasse a vida. Identificamos estas características como a imanência essencial do barroco. Este autor destaca ainda que os jesuítas, portanto católicos, desempenharam um enorme papel na Alemanha e Áustria nos séculos XVI e XVII, principalmente através dos dramas pedagógicos e moralizadores, Schul Dramen, que repercutiam com tal força na sociedade que mesmo os protestantes tinham que tomar frente a eles, o que viria a influenciar decisivamente o teatro alemão e torná-lo cada vez mais barroco através de suas temáticas e adereços.

Em um ensaio de Benjamin, Drama (Trauerspiel) y Tragedia (1993, 179184), se define a diferença entre tragédia e drama barroco com respeito à relação entre estes gêneros e a historicidade, mais especificamente a noção de tempo, que só pode ser percebido tendo a morte como ponto fixo. Na tragédia o herói morre segundo uma determinação externa para, ironicamente, ingressar na eternidade, ao passo que no drama a morte é um acontecimento que vem a dar respeitabilidade, vem a dar sentido, por assim dizer, aos acontecimentos da cena e às ações do personagem em vida. Uma morte digna é, no contexto dramático barroco, o corolário de uma vida bem vivida. Trata-se de um jogo, de uma reflexão, na qual os personagens todos participam até que a morte venha lhes indicar o fim da peça, assim como acontece conosco se encararmos nossa vida como uma representação e um palco. O tempo do drama, que não é o do mítico imemorável como na tragédia, corre em paralelo aos acontecimentos históricos, é um universo espectral, universo do que poderia ser ou ter sido, justamente para poder indicar suas similitudes com a realidade. Assim, opõe-se radicalmente a imanência e a historicidade do drama barroco ao caráter atemporal da tragédia grega. Segundo Benjamin $(1984,86)$ a diferença crucial entre tragédia e drama barroco é, portanto, que enquanto a primeira está colocada em um passado mitológico, por assim dizer fora do tempo, a segunda 
diz respeito a um fato concreto, temporalmente situado e, portanto, histórico. Dentro deste contexto, os personagens principais, geralmente aristocratas, que na tragédia servem para, entre outras coisas, dar a explicação mitológica da origem e identidade de um povo, estão no drama barroco como uma personificação da história.

Uma das diferenças do contexto das tragédias gregas para o dos dramas barrocos é, portanto, uma diferente noção de tempo. Enquanto o tempo grego é cíclico, o tempo judaico-cristão é linear; enquanto uma narrativa é mítica, a outra é histórica; enquanto uma é celebrativa, a outra é moralizante. (AUERBACH, 1994, passim) Assim, esta segunda narrativa, linear, histórica e moralizante, coloca o personagem mediante o signo indelével da culpa. Benjamin (1984, 108 et seq.) vai concordar com este aspecto de castigo ao falar sobre o soberano como criatura, dotado da fragilidade que lhe fará assumir uma atitude de temperança sobre o mundo, aproximando-se da apatia, e então da acedia melancólica, que o autor descreverá como causa de sua ruína. De acordo com esta argumentação, um rei que vê a si mesmo o faz, inevitavelmente, como um homem cercado de misérias. E torná-lo miserável é tão simples quanto a um homem comum, basta que se faça com que ele contemple sua imagem no espelho, e concluirá por si mesmo sobre a miséria de sua existência e a de todos os outros, a de tudo o mais.

A tristeza dos nobres não teria então, diferentemente da dos plebeus, preocupados com as necessidades materiais, uma causa imediata (BENJAMIN, 1984, 133 et 134), pois adviria de uma desgraça absoluta, inerente ao gênero humano e não decorrente de condições acidentais. O tempo linear e histórico traz consigo uma ameaça onipresente, a finitude. Esta finitude terá um papel importantíssimo no drama barroco alemão de maneira a transformar-se quase em sua obsessão, com os temas da morte, da caveira, da chacina, etc. Paradoxalmente, porém, esta inserção da historicidade causou um efeito contrário à intenção de dignificar as ações dos soberanos da cena e da vida: causou a impressão de que também a vida era uma mera representação, e não de atores, mas de fantoches, manipulados pelo destino trágico da morte. (BENJAMIN, 1984, 147) 
Em tal contexto, portanto: "O soberano representa a história." (BENJAMIN, 1984, 88) O drama barroco, como já dissemos, se diferencia da tragédia pela sua historicidade, na qual participa diretamente o personagem do soberano quase como a personificação desta história, e suas ações não servem a um fundo moral mais profundo do que o de denunciar os vícios e ressaltar as virtudes da corte. O contexto político da época não permitia um soberano diferente do modelo ditatorial, que se efetivava quase que muito mais por necessidade do que por vontade ou disposição própria. Por isto Hobbes escolhe o título de Leviatã para sua obra, por isto Maquiavel escreve O Princípe. O cetro que este monarca porta representa a sua capacidade de interferência no processo histórico na medida em que ele, no desempenho de suas funções, produz os fatos. O tiranicídio figurava como uma prática a ser debatida em prol de sua justificação, o que suscita as diversas preocupações mais centradas no mantenimento do poder, e da vida, do que com a conquista deste poder. Segundo Benjamin (1984, 88 et seq.), dentre os diversos meios de se alcançar o poder, usurpar o trono se evidenciava sempre o mais passível de ódio, e o mais suscetível de reação. O príncipe, como um soberano impedido de agir, assim como Hamlet, pensa no tiranicídio, mas hesita na autenticidade de sua vontade de eliminar o tio, mais odioso ainda por ter se casado com sua mãe e usurpado o trono de seu pai. Enquanto a função do soberano nos dramas barrocos é o de representar a história e ilustrar os acontecimentos da corte, ressaltando-Ihe as virtudes e as paixões, no plano concreto a finalidade última do soberano é evitar o estado de exceção, evitar as guerras, as calamidades, a peste, a fome, o que, muitas vezes, impele-o a tomar atitudes bruscas, o que pode caracterizá-lo como um tirano. O pesado véu da imanência absoluta pairando sobre o barroco oprime o homem deste período de tal maneira que ele se liga definitivamente às coisas transitórias e destinadas à extinção. Sentindose arrastado por elas, faz-se necessário que ele se junte e exalte todas as coisas do mundo em uma tentativa desesperada de salvá-las de sua consumição final, simultaneamente ao que salva a si mesmo.

Desta forma, apresenta-se ao nobre a ameaça da finitude, da morte, do estado de exceção, das guerras e catástrofes, que exigem medidas tão fortes que terminam por torna-lo um monstro. Enquanto soberano pode possuir reinos 
e castelos, súditos e exércitos, mas enquanto criatura como todas as outras, é possuidor apenas de sua honra, que nada mais é do que o reconhecimento dos outros pela sua pessoa, a autonomia de seu indivíduo regular. Da maneira que se apresenta, a honra é a possibilidade de ultrapassar a finitude, pois a fama de seus atos heroicos e de sua virtude continuará valendo mesmo após a sua morte, ainda que seja apenas vaidade. Mas é difícil o que não se configure em vaidade neste contexto barroco onde tudo é vaidade e vã aflição do espírito. A honra é, portanto, a defesa da fragilidade da vida impulsionada pela vaidade do espírito.

A arte do governo se refere ao comportamento ético ideal do soberano, que muito se aproxima da prática ascética estoica. (COUTINHO, 1994, 45) Se é por virtude de suas paixões que este soberano pode tornar-se de mártir em tirano, vendo ameaçada a sua soberania e sua vida, é através do domínio das paixões que ele virá a obter sucesso na tarefa de governar sabiamente e com virtude. Esta virtude, porém, aproxima-o cada vez mais da apatia melancólica. Percebe-se como, portanto, o estoicismo ressurge como uma tendência forte na filosofia do séc. XVII, ao lado apenas do ceticismo libertino. A retórica estoica, inspirada em Sêneca e nos demais escritores, poetas e filósofos da ldade de Prata do Império Romano, correspondente ao séc. I, vai antagonizar diretamente com a inspiração áurea ciceroniana dos escritores renascentistas. Nenhuma época, portanto, adequar-se-ia melhor a servir de inspiração ao séc. XVII do que a argêntea imperial, tanto retórica quanto filosoficamente, fato consumado pelo brilhantismo precursor de escritores como Montaigne, confessadamente inspirado nos antigos, com seus ensaios repletos de citações dos clássicos romanos, como Sêneca, Horácio, Lucrécio, Cátulo, Ovídeo, entre outros. Estas citações ocorrem diversas vezes, principalmente ao abordar um dos aspectos principais para nossa análise do barroco, a reflexão sobre a morte.

Uma vez que a imanência seja entendida como uma das características mais fundamentais do pensamento barroco, é necessário descrever e retomar uma de suas consequências psicológicas imediatas, a melancolia. Esta é entendida então como sentimento de vacuidade existencial e vista paradoxalmente enquanto dom e maldição de Saturno, ora como divindade pagã, e posteriormente um planeta dotado de grande influência astrológica. Consequentemente, tentaremos elucidar de que maneira esta divindade outrora 
positiva vai se transformando imageticamente na figura da morte através do desenvolvimento das reflexões sobre a melancolia ao longo da Idade Média.

\section{Melancolia}

A etimologia da palavra (KLIBANSKY; PANOFSKY; SAXL, 1991, 39) aponta melancolia como "bile negra", pois vem da união de duas palavras gregas, $\mu \varepsilon \lambda \alpha \sigma$, que significa negro, com $\chi 0 \lambda \eta$, bile. Notemos o que começa, desde já, a insinuar-se: a cor da bile que determina o comportamento é negra, e esta cor, ou melhor, ausência de cor, traz consigo uma carga fortíssima. Uma vez que é a cor do luto, já traça a conexão entre melancolia e morte e seus relativos, a noite, o ermo, o cemitério, o túmulo, os esqueletos, os animais noctívagos, o comportamento sombrio, entre outras características semelhantes.

Não é casual que a tragédia grega seja a narração de um dia na vida do herói, ao passo que o drama barroco se vincula às horas ermas da noite. (BENJAMIN, 1984, 122 et seq.) Ao passo que a tragédia antiga se passa durante o dia, acompanhando a trajetória do carro do sol, o drama barroco tem seu desenvolvimento temporal acolhido na frialdade noturna. Os fantasmas e espectros que habitam a escuridão personificam ininterruptamente a ameaça da finitude, e o papel importante da noite neste cenário é o de tornar mais fácil que o monstro da morte venha arrastar as criaturas, pois nas sombras ele se esconde melhor, e pode aparecer de surpresa.

Mas há um momento no qual a morte tem de entregar-se, pois sobre 0 mundo dos espíritos a história não exerce seu poder. Este momento é a meia noite, pois à meia-noite o tempo para, fazendo cessar a finitude, e possibilitando que aqueles que estão sob o jugo da morte tenham a oportunidade de voltar para assombrar os vivos ou exigir a vingança pela morte ignominiosa que sofreram. E é neste exato contexto que o pai de Hamlet aparece, abrindo a cena, no frio da meia-noite, para reivindicar a vingança por sua morte, o que irá restituir um sentido à existência melancólica do jovem príncipe, mas um sentido perverso, o da vingança: "Será sangrento o que eu pensar, daqui por diante, ou tudo o que eu pensar será irrelevante." (SHAKESPEARE, Ato IV, Cena IV: Hamlet) 
Assim como tudo que adquire importância ao nascer está cercado de vida, Hamlet, o personagem representativo desta melancolia, desta insatisfação existencial em relação ao mundo, que adquire sua relevância e sua referência a partir de seu ocaso, está cercado de morte. E isto porque, ao contrário dos homens comuns, ele sabe que sua existência é para a morte, que está morto muito antes de morrer efetivamente, que começa a morrer desde o momento em que nasce, testemunhando a efemeridade da vida, a transitoriedade do mundo. Esta inexorabilidade da finitude é a força elementar da natureza no processo histórico, mas seu fundamento reside em uma sensação de culpa a ser expiada, punida através do sacrifício da morte trágica. A culpa da criatura impulsiona a causalidade como instrumento de uma fatalidade inelutável, de maneira que a culpa, em forma de autoacusação, se aproxime muito de um conhecimento sobre si mesmo e sobre a natureza humana que raramente um sujeito consegue obter se não estiver sendo afligido pela afecção melancólica. "Tratai cada qual segundo seu próprio mérito, e quem há de escapar aos açoites?" (SHAKESPEARE, Ato II, Cena II: Hamlet)

Porém, esta lucidez da autoacusação não passou desapercebida à maioria dos que se dedicaram, oriundos das mais diversas matrizes conceituais, ao estudo do fenômeno da melancolia. Esta mesma negatividade a respeito de si mesmo e dos demais foi apontada por Freud em seu célebre texto sobre Luto e Melancolia, o qual traz como exemplo da auto recriminação justamente a situação do príncipe dinamarquês. (FREUD, 2010, 177) Neste texto, Freud aproxima-se da tradição filosófica quando, comparando o processo da melancolia ao processo do luto, postula aquele na incapacidade de substituir o objeto perdido e na incorporação da perda ao próprio sujeito, fazendo recair sobre si a ambivalência que tinha com o objeto amado, bem como a sombra deste objeto, para que possa, o eu, ser julgado como o próprio objeto ausente.

\footnotetext{
O melancólico ainda nos apresenta uma coisa que falta no luto: um extraordinário rebaixamento da autoestima, um enorme empobrecimento do Eu. No luto, é o mundo que se torna pobre e vazio; na melancolia é o próprio Eu. O doente nos descreve seu Eu como indigno, incapaz e desprezível; recrimina e insulta a si mesmo, espera rejeição e castigo. (FREUD, 2010, 175 et 176)
} 
Essa comparação demonstra que a melancolia é um luto pela perda de si mesmo, pela sensação de estar morto em vida, uma vez que o mundo não tenha o sentido fundamentador da existência. Não permitindo que uma explicação fantasiosa venha a preencher a lacuna que a pergunta pelo sentido deixou aberta, o sujeito melancólico aferra-se a uma posição de defesa da vacuidade do sentido, da nadificação, e passa a ser o portador da morte. E é assim que, muito longe de abandonar o mundo a sua própria consumação, o filósofo melancólico, ainda que cerrado em si, tenta interiorizar as coisas da mesma maneira que interiorizou o seu objeto primordial que se ausentou, de forma que é na repetição deste processo de abandono que ele vai formando os conceitos, que ele continua teorizando, que ele produz filosofia, como maneira de preencher o seu vazio, o vazio da verdade que encontrou, e simultaneamente salvar as coisas, as criaturas, a efetividade.

Voltando ao príncipe melancólico através da bela análise de Lacan (1986, 18 et seq.), percebemos como a tragédia de Hamlet pode ser encarada como a tragédia do desejo humano, na medida em que este desejo seja entendido como o fator integrador dos cacos do sujeito, aquilo que Ihe dá uma forma, uma coesão. Esta tragédia está tomada, de uma ponta a outra, pela dimensão do luto, que, assim como no pensamento de Benjamin, é resultante de um crime original, o crime do saber. "A dimensão intolerável oferecida à experiência humana, não é a experiência da própria morte, que ninguém tem, mas da morte de um outro." (LACAN, 1986, 74) Entre o ser e o não ser há a dor, há a culpa por existir, da qual padece esse príncipe, e o saber é o seu pecado consciente. Mas o desejo que integra o sujeito não é um desejo próprio, e sim um desejo de um outro, ao qual este sujeito se reporta, e a questão de Hamlet é a respeito da tarefa que seu pai, vindo da própria morte, Ihe outorga. Assim, podemos perceber o quanto o drama de Hamlet, considerado por especialistas em literatura (BLOOM, 2001, 485 et passim) o mais profundo dos dramas barrocos e de seu protagonista 0 mais inteligente dos personagens da literatura ocidental, é orientado pela morte desde seu início, pois é com a aparição do fantasma do Rei Hamlet que Shakespeare abre a primeira cena, através da qual se evidencia que a alteridade é uma alteridade morta. Lacan $(1986,46)$ destaca ainda a ausência de transcendência na tragédia de Hamlet, ponto no qual viemos insistindo, dizendo 
que não há outro do outro, ou seja, que não há uma verdade desvelada, e sim uma verdade sem verdade, que a tarefa, a demanda, nunca será claramente apresentada, de maneira que o sujeito permaneça errante, sempre a procurar 0 que estará sendo esperado dele. Esta verdade sem verdade é alegórica, e esta busca incessante por ela só se faz segundo os preceitos da melancolia. E esta alegoria da verdade é a configuração do mundo representativo, é o cerne da alegoria barroca. A alegoria barroca, devido à imanência, é uma alegoria da morte.

Segundo Marie-Claude Lambotte (2000, 87 et seq.), a verdade do melancólico se liga diretamente à decepção, decepção esta que se fez crer ao sujeito indispensável, que se fez crer uma lei inexorável do destino. Imerso nesta decepção, o melancólico é o mensageiro da morte, que detém um saber que o anula por excesso de verdade. Sua verdade é a do logro primordial no qual se baseia a ilusão da unidade da identidade, no logro que constitui a sistematização do mundo como um esquema pleno de sentido. Este é o seu nó fundamental do conhecimento, revelado por uma verdade precoce demais, "[...] o Saturno romano que levanta o véu da verdade em uma cena da vida doravante congelada [...]" (LAMBOTTE, 2000, 87). A ausência de sentido foi por ele concluída a partir de uma problemática filosófica universal, com a qual ele mesmo se identifica.

\section{A imagem de Saturno: imanência e finitude}

De acordo com Klibansky, Panofsky e Saxl (1991, 199 et seq.), as representações pictóricas de Saturno na arte clássica, e sua influência nas representações medievais e pré-renascentistas, o colocam em duas visões diferentes. Em uma, ele é representado de forma enérgica, imponente, com a foice na mão, em uma representação do tempo, como que ameaçando a todos os que lhe estão em torno e o contemplam. Em outras figuras, este deus aparece cabisbaixo, de olhar vago, apoiado sobre uma das mãos, segurando seus instrumentos displicentemente. Apenas no fim da Idade Média é que os artistas começam a se desprender das representações clássicas e orientais e passam a compor a imagem de Saturno, assim como de outros planetas, de forma mais livre. Ele passa a ser assimilado à imagem de um velho camponês, 
provavelmente por herança da tradição romana que o tinha como um deus agrícola, e fica, em virtude disto, relegado a camada mais baixa da sociedade feudal. Isto não impede, claro, que ele seja mostrado, em outras obras, como monarca soberano e senhor do tempo, pairando por sobre a terra e exercendo a sua influência maléfica sobre seus filhos enquanto devora criancinhas, sem a maioria das características que a astrologia por tradição Ihe atribuía. Sua foice, antes transformada em gadanho, como que para aproximá-lo dos camponeses, pode aparecer como cetro ou até mesmo como bengala, para demonstrar, respectivamente, sua soberania e seu caráter de ancião doentio e sinistro. É na Baixa Idade Média que os aspectos negativos de Saturno começam a predominar, fazendo com que ele ganhe uma aura demoníaca e salientando sua perversidade. (KLIBANSKY; PANOFSKY; SAXL, 1991, 195)

Este astro maligno, ainda que outros bons astros lhe façam frente, sempre acha uma maneira de perpetrar suas maldades, se não pode ferir quem desejava, trata de fazer o maior mal possível a quem quer que possa:

Verum est, quod permutatur ab eius influentia secundum potentia alterius planetae ipsum superantis, et tamem, si non potest operari suam malitiam in alio quantum vellet, nocet omnibus quantum potest. (ALBUMASAR apud KLIBANSKY; PANOFSKY; SAXL, 1991, 195)

Assim, o tratamento dado ao planeta Saturno na astrologia se estende e coaduna-se à visão que é tida de seus filhos, os melancólicos, segundo a medicina e a teoria humoral, chegando a figurarem, por transposição, as características de um aos outros, de modo a inverter a visão do melancólico como homem de gênio que havia na antiguidade, e defendida na Problemata $X X X, I$, para uma melancolia estritamente pejorativa. A linearidade do tempo, domínio de Saturno, contribui para relacioná-lo aos aspectos sombrios e à figura da morte, terminando por transformá-lo de divindade da agricultura, representado no calendário sazonal, em demônio do tempo e senhor da morte.

O governante dos meses, 'o deus grego do tempo e o demônio romano das sementeiras' transformaram-se na morte ceifadora, com sua foice, que agora não visa mais os cereais, mas a espécie humana, da mesma forma que a passagem do tempo não é mais caracterizada pelo ciclo anual da semeadura, da colheita e do repouso invernal da terra, mas pelo implacável trajeto da vida em direção à morte. (BENJAMIN, 1984, 173)

Doutor em Estética e Filosofia da Arte. Professor na Unidade de Ciências Humanas de Passo Fundo (RS). Brasileiro, residente em Passo Fundo - RS. Email: fcofianco@gmail.com 
De acordo com Klibansky, Panofsky e Saxl (1991, 190), é Bernardo Silvestre quem, no séc. XII, faz a passagem da figura de Saturno para a figura da morte, apresentando-o como um planeta maléfico, pictoricamente representado com os traços de um velho descarnado, semelhante a um esqueleto, o que denunciava a sua condição de deus decadente e antigo, portando uma gadanha, com a qual, a exemplo do tempo, sua identificação, ceifava a vida dos seres, ao invés dos cereais, como fazia na mitologia romana, era a antecipação do ícone da morte, tão largamente difundido em época posterior.

Saturno é aqui o ceifador, cujo gadanho afiado destrói tudo o que é bonito e dá flor: ele não deixa florescer rosas nem lírios, nem tolera a frutificação. Em um só aspecto é digno de veneração: o de ser filho da eternidade, 0 pai do tempo. (SILVESTRE apud KLIBANSKY; PANOFSKY; SAXL, 1991, 189)

Com sua lâmina, é responsável não apenas pela morte física, mas também pela morte em vida, pela falta de estímulo, pelos desligamentos traumáticos da vida humana, e, como consequência destes desligamentos, um desprendimento do mundo e do corpo que o habita, frieza, insensibilidade, desistência de si, auto anulação, renúncia, amargura de viver, pessimismo e melancolia. Indubitavelmente, a identificação de Saturno como dotado de uma natureza sombria e perniciosa teve grande influência na posterior assimilação de sua imagem ao estado melancólico, enquanto este é visto pejorativamente. Saturno é, desde então, representado como um sombrio senhor celeste, expulso do panteão divino, comportando-se perante o mundo com uma declarada hostilidade.

Atravessando os séculos, a identificação de Saturno com a morte presentifica a onipotência da finitude sobre as criaturas, principalmente no Barroco, onde, segundo Benjamin $(1984,125)$, a miséria da criatura era sentida de uma forma clara, através da imanência. Daí decorre a omnipotência da melancolia sobre as criaturas, da presença da finitude, do próprio abismo.

\section{CONCLUSÃO}


Retomando as últimas considerações sobre alegoria e capacidade interpretativo-filosófica, destaca-se que a moralidade não é a única possibilidade de fundamentação existencial em um mundo vazio e carente de sentido no qual o sujeito é constantemente ameaçado pela negatividade e pela finitude. Essa pluralidade semântica alegórica deixa entrever que existe um objeto de saber escondido na relação estética com o mundo, o que abre uma nova perspectiva para a fuga da condição de efemeridade do mundo. A arte traz, além da beleza, o conhecimento. Surge a filosofia, ao lado da arte, como alternativa ao melancólico, que pode, através dela, desvendar o que há de perene por trás desta beleza e fazer desta tarefa o sentido de sua existência, possibilitando uma vitória simbólica sobre a morte.

Assim, enquanto o conceito é visto como fixo, como uma homogeneização, assemelha-se a um rótulo, e como rótulo, jamais pode representar perfeitamente a coisa, tampouco filiá-la à ideia. Aí, justamente, reside a importância da alegoria, do conceito flexível, como possibilidade de salvar as ideias e fazer justiça às coisas destruídas, ao mundo em ruínas e às pessoas mortas. A melancolia, sinal da profundidade intelectual saturnina, pode desenvolver uma intuição quase premonitória. A melancolia seria um oráculo infalível e monocórdico; quando interrogado sobre o que vê no futuro ela responderia: 'Eu vejo morte!' A morte é a verdade a ser interpretada, a morte é o que Saturno possibilita a seus filhos melancólicos preverem. Toda a alegoria do drama barroco, sob o símbolo da imanência, é uma representação da morte que faz refletir sobre o que se está fazendo com a própria vida.

Mas é a imanência que dá à melancolia do período barroco a sua legitimidade. É pela finitude, pela presença constante da morte sem perspectiva de transcendência, sem esperança de redenção, que o pensamento filosófico eflui e se desenvolve. É a partir da dúvida melancólica a respeito de sua própria existência que a subjetividade moderna vai se erguer e desenvolver. As figuras do anjo alado que perece a sua tristeza apesar das diversas potencialidades que tem, e do ancião descarnado ameaçadoramente brandindo sua foice $\mathrm{e}$ mostrando a ampulheta, são intrinsecamente relacionadas e se ligam diretamente ao pensamento filosófico. É na meditação sobre a morte e a própria finitude que reside a busca de sentido para a própria vida, o que é dificultado 
num contexto cultural marcadamente imanente, pois este sentido existencial é sempre relativo a uma determinada possibilidade de transcendência, não necessariamente religiosa ou espiritual, metafísica, e sim existencial, ou seja, projetar algo que lhe ultrapasse e agir de acordo a alcançá-lo, como o cavaleiro que passa indiferente aos que lhe ameaçam em direção de sua longínqua fortaleza de virtude. Quando não há esta possibilidade, portanto, de criação e identificação de um sentido, o sujeito padece a melancolia, que é a sensação da vacuidade ontológica, que é, alegoricamente, não conseguir fixar-se em um sentido absoluto num mundo, no qual se pode escolher livremente entre diversos sentidos diferentes, de modo que nenhum deles é o sentido último e é capaz de dar aquela satisfação existencial de um mundo pleno de sentido. Podemos perceber aí, neste contexto, o gênese da subjetividade moderna: autônoma, irremediavelmente livre, lúcida e racional, mas ao mesmo tempo irônica, desestabilizada, ensaística, ou, por outro lado, metódica aos extremos da rigorosidade obsessiva, alçada ao estatuto de fundamento metafísico, mas em constante dúvida em relação a existência verdadeira do mundo.

\section{REFERÊNCIAS}

AUERBACH, Erich. A Cicatriz de Ulisses. In__: Mímesis. São Paulo: Perspectiva, 1994, p. 1-20.

BENJAMIN, Walter. Drama (Trauerspiel) y Tragedia. In__: La metafísica de la juventud. Tradução espanhola de Luis Martinez de Velasco. Barcelona, Espanha: Paidós, 1993, p. 179-184.

BENJAMIN, Walter. Origem do Drama Barroco Alemão. Tradução, apresentação e notas de Sérgio Paulo Rouanet. São Paulo: Brasiliense, 1984.

BENJAMIN, Walter. Origem do Drama Trágico Alemão. [] Edição e Tradução de João Barrento. Belo Horizonte: Autêntica, 2016.

BENJAMIN, Walter. Ursprung des deutschen Trauerspiels. Frankfurt am Main: Suhrkamp, 1996.

BLOOM, Harold. Hamlet. In_ : Shakespeare: a invenção do humano. Rio de Janeiro: Objetiva, 2001, 479-535. 
COUTINHO, Afrânio. Do Barroco. Rio de Janeiro: Tempo Brasileiro e Editora da UFRJ, 1994.

DUBOIS, Claude-Gilbert. O Imaginário da Renascença. Brasília: UnB, 1995.

FREUD, Sigmund. Luto e Melancolia. In__: Introdução ao Narcisismo, Ensaios de Metapsicologia e Outros textos. Tradução de Paulo César de Souza. São Paulo: Companhia das Letras, 2010, p. 170-194. Coleção Sigmund Freud Obras Completas em 20 Volumes Coordenada por Paulo César de Souza. Volume FREUD (1914-1916).

HATZFELD, Helmut. Estudos sobre o Barroco. São Paulo: Perspectiva e Editora da Universidade de São Paulo, 1988.

KLIBANSKY, Raymond; PANOFSKY, Erwin; SAXL, Fritz. Tradução espanhola de María Luisa Balseiro. Saturno y la melancolía. Madrid: Alianza Editorial, 1991.

LACAN, Jacques. Hamlet por Lacan. Tradução de Cláudia Berliner. São Paulo: Escuta/LiuBliú, 1986.

LAMBOTTE, Marie-Claude. Estética da Melancolia. Tradução de Procópio Abreu. Rio de Janeiro: Companhia de Freud, 2000.

SHAKESPEARE, William. Hamlet. Tradução interlinear e notas de Elvio Funck. São Leopoldo: Unisinos, 2003.

SHATTUCK, Roger. Conhecimento Proibido. São Paulo: Companhia das Letras, 1998.

TOBIEN, Felicitas. Dürer und seine Zeitgenossen. Ramerding: Berghaus, 1985. 